\title{
Effect of oral nimodipine on cerebral infarction and outcome after subarachnoid haemorrhage: British aneurysm nimodipine trial
}

\author{
J D Pickard, G D Murray, R Illingworth, M D M Shaw, G M Teasdale, P M Foy, P R D Humphrey,
} D A Lang, R Nelson, P Richards, J Sinar, S Bailey, A Skene

\begin{abstract}
Wessex Neurological Centre, Southampton General Hospital, Southampton SO9 4XY J D Pickard, MCHIR, professor of clinical neurological sciences R Nelson, FRCS, senior registrar in neurosurgery S Bailey, RGN, Medical Research Council research sister
\end{abstract}

Medical Statistics Unit, Department of Surgery, University of Glasgow, Glasgow G11 6NT G D Murray, PHD, senior lecturer in medical statistics

Regional Neurosciences Centre, Charing Cross Hospital, London W6 8RF

R Illingworth, FRCS, consultant neurosurgeon P Richards, FRCS, consultant neurosurgeon

\section{Mersey Regional}

Department of Medical and Surgical Neurology,

Walton Hospital, Liverpool L9 1AE

M D M Shaw, FRCS,

consultant neurosurgeon

P M Foy, FRCS, consultant neurosurgeon

P R D Humphrey, MRCP, consultant neurologist

Institute of Neurological Sciences, Southern

General Hospital, Glasgow G51 4TF

G M Teasdale, FRCS,

professor of neurosurgery

D A Lang, FRCS, registrar in neurosurgery

J Sinar, FRCS, registrar in

neurosurgery

Department of

Mathematics, University of Nottingham, Nottingham NG7 1RD

A Skene, PHD, senior lecturer in medical statistics

Correspondence to:

Professor Pickard.

Br.11ed f 1989:298:636-42

\section{Abstract}

Objective-To determine the efficacy of oral nimodipine in reducing cerebral infarction and poor outcomes (death and severe disability) after subarachnoid haemorrhage.

Design-Double blind, placebo controlled, randomised trial with three months of follow up and intention to treat analysis. To have an $\mathbf{8 0} \%$ chance with a significance level of 0.05 of detecting a $50 \%$ reduction in an incidence of cerebral infarction of $15 \%$ a minimum of 540 patients was required.

Setting-Four regional neurosurgical units in the United Kingdom.

Patients-In all 554 patients were recruited between June 1985 and September 1987 out of a population of 1115 patients admitted with subarachnoid haemorrhage proved by the results of lumbar puncture or computed tomography, or both. The main exclusion criterion was admission to the neurosurgical units more than 96 hours after subarachnoid haemorrhage. There were four breaks of code and no exclusions after entry. One patient was withdrawn and in 130 treatment was discontinued early. All patients were followed up for three months and were included in the analysis, except the patient who had been withdrawn.

Interventions-Placebo or nimodipine $60 \mathrm{mg}$ was given orally every four hours for 21 days to $\mathbf{2 7 6}$ and 278 patients, respectively. Treatment was started within 96 hours after subarachnoid haemorrhage.

End points - Incidence of cerebral infarction and ischaemic neurological deficits and outcome three months after entry.

Measurements-Demographic and clinical data, including age, sex, history of hypertension and subarachnoid haemorrhage, severity of haemorrhage according to an adaptation of the Glasgow coma scale, number and site of aneurysms on angiography, and initial findings on computed tomography were measured at entry. Deterioration, defined as development of a focal sign or fall of more than one point on the Glasgow coma scale for more than six hours, was investigated by using clinical criteria and by computed tomography, by lumbar puncture, or at necropsy when appropriate. All episodes of deterioration and all patients with a three month outcome other than a good recovery were assessed by a review committee.

Main results-Demographic and clinical data at entry were similar in the two groups. In patients given nimodipine the incidence of cerebral infarction was $22 \%(61 / 278)$ compared with $33 \%(92 / 276)$ in those given placebo, a significant reduction of $34 \%$ ( $95 \%$ confidence interval 13 to $50 \%$ ). Poor outcomes were also significantly reduced by $40 \% \quad(95 \%$ confidence interval 20 to $55 \%$ ) with nimodipine (20\% $(55 / 278)$ in patients given nimodipine $v 33 \%(91 / 278)$ in those given placebo). Adverse reactions were reported in 14 patients given nimodipine and 10 given placebo.
Conclusions-Oral nimodipine $60 \mathrm{mg}$ four hourly is well tolerated and reduces cerebral infarction and improves outcome after subarachnoid haemorrhage.

\section{Introduction}

Despite advances that have reduced considerably the risks of operation to secure a ruptured cerebral aneurysm the overall mortality and morbidity during the management of patients with subarachnoid haemorrhage who have survived and not been devastated by the initial ictus has not fallen dramatically. This is mainly because such patients rebleed and have delayed cerebral ischaemia. The management dilemma remains the need to weigh the risk of precipitating cerebral ischaemia by operation against that of rebleeding while awaiting surgery.

Subarachnoid haemorrhage provides the clearest clinical opportunity for pretreating ischaemia, but, although the calcium antagonist nimodipine has been reported to reduce the incidence of delayed cerebral ischaemia after subarachnoid haemorrhage, ${ }^{12}$ definitive evidence is lacking. Previous trials were small and relied on selecting a subgroup of patients with cerebral ischaemia presumed to be due to cerebral vasospasm. Ischaemia may be the result of several factors $^{3-5}$ and cannot be attributed simply to an exaggerated contraction of cerebral arteries (vasospasm); thus defining such a subgroup is difficult and ignores any potential benefit of treatment in other causes of ischaemia.

Nimodipine has various effects on the cerebral circulation, not all of which may be beneficial. Cerebrovascular smooth muscle is more sensitive than systemic arterial smooth muscle to changes in extracellular calcium concentration and to calcium antagonists such as nimodipine. ${ }^{6.8}$ In addition to being a moderate cerebral vasodilator, however, nimodipine impairs cerebrovascular reactivity. ${ }^{9-11}$ Nimodipine does not reduce the incidence or severity of cerebral vasospasm detected by angiography in humans or primates, ${ }^{12 \cdot 17}$ but it reduces the size of cerebral infarcts in rats when given before but not after occlusion of a cerebral artery. ${ }^{18}$

We therefore conducted a prospective trial to establish the effect of nimodipine on the incidence of both ischaemic events and proved cerebral infarction and on outcome after subarachnoid haemorrhage.

\section{Patients and methods}

SELECTION OF PATIENTS AND DIAGNOSIS

Eligible patients were admitted to one of four centres (in London, Southampton, Liverpool, and Glasgow) within 96 hours after the onset of symptoms and signs of subarachnoid haemorrhage. This time limit was specified because our hypothesis was that nimodipine should be given soon after the bleed to have a prophylactic effect upon subsequent ischaemia. The diagnosis was confirmed by lumbar puncture or 
computed tomography, or both - angiography was not required before admission to the trial. The reasons for exclusion were pregnancy; major renal, hepatic, or pulmonary disease; pre-existing cardiac decompensation or a recent (within six months) myocardial infarction; age below 18 years; a subarachnoid haemorrhage that produced a coma in the week preceding the most recent subarachnoid haemorrhage; and the patient or relative being unwilling to give consent. Eligibility for the trial was checked in specially designed record forms with a check list of entry and exclusion criteria. A separate record was kept of patients who did not fulfil the entry criteria. Patients' eligibility was rechecked during outcome review meetings of all the centres. There were no exclusions. Written informed consent was obtained from the patient, care having been taken to avoid undue stress, or from a relative. The ethical committee of each centre approved the study and the Department of Health and Social Security supplied a clinical trial exemption for the drug before the start of the study.

\section{DESIGN OF STUDY}

Our aim was to establish with a prospective, multicentre, randomised, double blind, placebo controlled trial whether oral nimodipine $(60 \mathrm{mg}$ every four hours) reduced the incidence of episodes of cerebral ischaemia and cerebral infarction arising anew after spontaneous intracranial haemorrhage from a cerebral aneurysm. The outcome events to be specifically examined prospectively were the incidences of cerebral infarction and ischaemic deficit and the outcome three months after the bleed, with the principle distinction being between a moderate or good recovery and a bad outcome (death or severe disability). Each of the centres had experience with similar large studies of dipyridamole, ${ }^{19}$ antifibrinolytic treatment, ${ }^{20}$ or computed tomography ${ }^{21}$ in patients with subarachnoid haemorrhage. From these results we expected that at least $15 \%$ of control patients would have a poor outcome attributable to cerebral infarction. A minimum of 540 patients was required for the trial to have an $80 \%$ chance with a significance level of 0.05 of detecting a $50 \%$ reduction in an incidence of cerebral infarction of $15 \%$.

\section{RANDOMISATION}

Patients were randomised to treatment or placebo by using separate randomisation lists for each centre balanced in blocks of four. Bayer UK supplied the pharmacy in each centre with bottles containing tablets of either nimodipine or placebo. Bottles were numbered consecutively and assigned to eligible patients in that order. Each centre was supplied with cards that could break the code for each patient individually and be used if the doctor in charge of the patient decided that the code needed to be broken.

\section{TREATMENT}

Treatment was started within 96 hours after ictus and routinely continued for 21 days in survivors, unless there were clinical indications for stopping. Nimodipine (or matching placebo) was given as fast release tablets containing $30 \mathrm{mg}$ active compound (two tablets given orally every four hours). The dose was based on the results of previous studies. ${ }^{1322}$ Tablets were swallowed with water, or if the patient was unable to swallow the tablets were crushed and washed down a nasogastric tube with normal saline. The protocol allowed for adjustment of the dose if hypotension occurred, but this was not found to be necessary. Compliance was checked while the patient was in the neurosurgical unit by comparing the number of tablets prescribed with the number taken. Any patient who missed more than one third of the daily dose on any day was deemed to be non-compliant. The protocol allowed for separate analysis of this group, but this was found not to be necessary. Plasma samples were taken from 35 patients (eight taking placebo, 27 nimodipine) and nimodipine concentrations measured - there was no evidence of patients given placebo receiving active treatment, or vice versa.

\section{CLINICAL MONITORING}

The severity of subarachnoid haemorrhage was graded according to an adaptation of the Glasgow coma scale, ${ }^{23}$ which is similar to the scale recently adopted by the World Federation of Neurosurgical Societies. ${ }^{2+}$ Patients whose clinical grade was I had a score on the Glasgow coma scale of 15 and were neurologically intact, apart from having cranial nerve palsy. Those in grade II had a score of 15 and were neurologically intact, apart from having cranial nerve palsy, with neck stiffness or headache, or both. Those in grade III had a score of 13-14 and were with or without neurological deficit and those in grade IV a score of 8-12 with or without neurological deficit. Finally, those in grade $\mathrm{V}$ had a score of 3-7 and were in a coma with or without abnormal posturing.

Computed tomography was performed within 24 hours after admission to the trial and repeated whenever necessary if the patient's clinical condition deteriorated at all. Angiography, operation, and other aspects of management remained the responsibility of the consultant in charge of the patient. The cause of subarachnoid haemorrhage was determined by angiography or at necropsy or, in two cases, from the typical appearance of a giant aneurysm on a computed tomogram.

Patients were monitored clinically throughout their time in hospital: blood pressure, pulse rate, and neurological observations were recorded. Particular attention was paid to the patient's degree of consciousness, focal neurological features, and symptoms and signs suggestive of rebleeding, ischaemia, or another adverse event.

The minimum criterion to define deterioration was either development of a focal sign or a decline by more than one point on the Glasgow coma scale for more than six hours. The aetiology of deterioration was investigated by using clinical criteria with results from computed tomography whenever possible; when appropriate it was investigated by lumbar puncture or at necropsy. All episodes of deterioration and all patients whose outcome at three months was not a good recovery were assessed at regular meetings of a review committee comprising representatives from each of the four centres. The review committee assessed outcome blind to allocated treatment. Causes of deterioration were classified as rebleed, cerebral ischaemia or infarction, or other, when the specific complication was recorded. The diagnosis of rebleeding or of ischaemia or infarction was classified as definitive or probable according to whether confirmatory evidence was available from computed tomography, from an operation, or at necropsy.

A patient with two infarcts was counted once for the statistical analysis of cerebral infarction. If a patient had both a rebleed and an infarct he (she) appeared in both analyses. Deterioration in a patient known to have an intracerebral haematoma was deemed to be due to ischaemia if as the new signs developed there was a growing area of low density surrounding a clot that had not itself increased on computed tomography. Outcome was assessed at least three months after entry to the trial according to the five point Glasgow outcome scale $^{25}$ by a doctor who was not responsible for the patient's early management or by postal or telephone inquiry when a patient had moved out of the region. In patients who were dead or disabled at three months we 
assessed whether the cause was a direct effect of the initial bleed, cerebral ischaemia or infarction, rebleeding, hydrocephalus, intracranial haematoma, operative complication, another complication of treatment, or other. In five cases there was sudden death with no clinical evidence or evidence from computed tomography, from lumbar puncture, or at necropsy of the cause; these were classified as sudden death of unknown cause.

\section{STATISTICAL ANALYSIS}

The two treatment groups were compared for rates of infarction (primary outcome event), poor outcome (secondary outcome event), and rebleeding by using $\chi^{2}$ tests. These analyses were supported by a detailed analysis that used stepwise logistic regression to adjust the comparisons for the effects of any chance imbalance in the prognostic factors identified from an earlier study ${ }^{20}$ with the addition of data from computed tomography. Interaction terms between the prognostic factors and treatment were included in the models to test whether any treatment effects were confined to particular subgroups of patients. The prognostic factors considered in this analysis were age; sex; loss of consciousness at ictus; time from haemorrhage to entry; score on the Glasgow coma scale on entry; limb weakness, neck stiffness, and headache (all on entry); hypertension (defined by a history of hypertension, receiving hypertensive treatment on entry, or a diastolic blood pressure greater than $100 \mathrm{~mm} \mathrm{Hg}$ on entry); angiographic findings (positive, negative, or not done); and computed tomographic findings (normal, abnormal, or not done).

All clinical data generated during the study were recorded in the patients' record forms by us - the blue National Cash Register copy was sent monthly to Bayer UK (Dr L Porto) to comply with Department of

TABLE I-Demographic data on and indices of severity of initial subarachnoid haemorrhage in patients treated with nimodipine or placebo. Values are numbers of patients unless stated otherwise

\begin{tabular}{|c|c|c|}
\hline & $\begin{array}{l}\text { Patients taking nimodipine } \\
\qquad(\mathrm{n}=278)\end{array}$ & $\begin{array}{l}\text { Patients taking placebo } \\
\qquad(\mathrm{n}=276)\end{array}$ \\
\hline Mean (SD) age (years) & $46(13)$ & $48(12)$ \\
\hline Men & 114 & 107 \\
\hline Women & 164 & 169 \\
\hline Alcohol abuse & 12 & 5 \\
\hline Diabetes mellitus & 4 & 3 \\
\hline Chronic airways disease & 5 & 7 \\
\hline Peripheral vascular disease & & 2 \\
\hline Smoker ( $>10$ cigarettes/day) & 120 & 143 \\
\hline Other cardiovascular disease & 2 & 11 \\
\hline $\begin{array}{l}\text { Other diseases } \\
\text { S }\end{array}$ & 28 & 33 \\
\hline \multicolumn{3}{|l|}{ Hypertension: } \\
\hline History & 33 & 23 \\
\hline Being treated at entry & 20 & 16 \\
\hline Present at entry & 40 & 35 \\
\hline Any feature & 71 & 52 \\
\hline Abnormal electrocardiogram on admission & 28 & 33 \\
\hline Previous subarachnoid haemorrhage & 37 & 43 \\
\hline Loss of consciousness at ictus & 126 & 129 \\
\hline \multicolumn{3}{|l|}{ Clinical grade: } \\
\hline I & 8 & 12 \\
\hline II & 168 & 159 \\
\hline III & 76 & 72 \\
\hline IV & 19 & 25 \\
\hline $\mathrm{V}$ & 7 & 8 \\
\hline Initial computed tomography & 273 & 276 \\
\hline Time from ictus to scan (days) & 1.5 & 1.5 \\
\hline Normal results & 35 & 45 \\
\hline Cisternal blood ( $>2 \mathrm{~mm}$ thick) & 177 & 168 \\
\hline Intracerebral haematoma & 58 & 61 \\
\hline Intraventricular blood & 83 & 83 \\
\hline Hydrocephalus & 34 & 36 \\
\hline Angiography & 243 & 229 \\
\hline Time from ictus to angiography (days) & $5 \cdot 5$ & $5 \cdot 1$ \\
\hline \multicolumn{3}{|l|}{ Aneurysm: } \\
\hline Proved & 187 & 181 \\
\hline Multiple & 40 & 29 \\
\hline Carotid. & 68 & 54 \\
\hline Anterior cerebral & 81 & 83 \\
\hline Middle cerebral & 54 & 49 \\
\hline Posterior circulation & 20 & 15 \\
\hline & 54 & 46 \\
\hline \multicolumn{3}{|l|}{ Operations: } \\
\hline No & 165 & 154 \\
\hline Time from ictus to operation (days) range) & $10 \cdot 8(2-60)$ & $11 \cdot 3(2-116)$ \\
\hline
\end{tabular}

Health and Social Security (clinical trial exemption) regulations, the pink copy to GDM, and the white copies were kept in each centre. GDM and AS (for Bayer UK) analysed the data independently.

\section{Results}

Between June 1985 and September 1987, 554 patients were recruited into the trial out of a total population of 1115 patients admitted to the four centres with a diagnosis of subarachnoid haemorrhage: 151 in Southampton, 101 in London, 199 in Glasgow, and 103 in Liverpool. A total of 108 patients did not fulfil the entry criteria for the trial in Southampton, 207 did not in Liverpool, 214 in Glasgow, and 32 in London. The most common reason for not fulfilling the entry criteria was a delay of more than 96 hours between bleeding and admission (317 patients). All but two patients were entered within the time limit of 96 hours; these two patients remained in the analysis as they had violated the criterion by less than 24 hours. The mean time from ictus to entry was 1.9 days.

One patient withdrew his verbal consent after randomisation (placebo group) but before he had signed the consent form or received any treatment. His case was fully documented and followed up to three months (he made a good recovery) but was not included in the statistical analysis. There were four breaks of code in two centres: sudden hypotension with induction of anaesthesia (placebo), jaundice of unexplained cause (placebo), sudden intraoperative hypotension (placebo), and jaundice shown at necropsy to have been due to rupture of an aortic aneurysm (nimodipine). Treatment was discontinued within 21 days in 130 patients ( 70 given nimodipine, 60 placebo), the main reason being a negative result on angiography with no evidence of an imbalance between treatments ( 87 patients).

The cases of 272 patients were reviewed by the committee. No patients were lost to follow up. All patients recorded as survivors were known to be alive 90 days after entry.

\section{DEMOGRAPHIC AND CLINICAL DATA}

The demographic data and various indices of severity of subarachnoid haemorrhage (table I) show the overall comparability of the treatment groups. The group given nimodipine had a higher prevalence of hypertension, neck stiffness, and non-reacting pupils, factors generally considered prognostic of poor outcome. The group given placebo, however, contained more patients with a history of cardiovascular disease and a higher number of smokers.

\section{INTERCENTRE VARIABILITY}

The overall comparability of the two groups was maintained within centres but there were differences among the four centres, reflecting different patterns of referral, systemic disease, and resources.

In London older patients (mean age 50) were entered earlier (mean 1.4 days, with fewer admissions too late for entry $(14 \%(19 / 133))$. The patients were slightly more hypertensive, with a longer duration of unconsciousness at ictus (in $11 \%(11 / 101)$ it was over 24 hours), a lower clinical grade $(55 \%(55 / 101)$ had a good grade), and less neck stiffness (7\% (7/101)); angiography and operations were performed much later (mean of 11 and 19 days, respectively).

In Southampton patients were entered latest ( $2 \cdot 3$ days) and there was a higher prevalence of previous subarachnoid haemorrhage $(23 \%(35 / 151))$ and loss of consciousness at ictus $(54 \%(82 / 151))$ and less headache $(25 \%(35 / 142))$. Computed tomography yielded more normal results $(25 \%$ (37/147)), with 
fewer proved aneurysms (56\% (84/151)). Computed tomography in the patients treated with nimodipine yielded fewer normal results $(17 \%(12 / 72))$ than in those given placebo $(33 \%(25 / 75))$.

In Liverpool the greatest number of patients were admitted too late for entry $(39 \%(122 / 310))$, the prevalence of loss of consciousness at ictus was lowest $(30 \%(31 / 103))$, lumbar puncture studies were used the most for diagnosis $(91 \%(94 / 103)$; range $46-55 \%$ in the other centres), and patients had the best overall grade.

In Glasgow the prevalence of aneurysms was greatest $(77 \%(154 / 199))$, including multiple aneurysms $(27 \%$ (40/150 angiograms)), and the prevalence of reported alcohol abuse was lowest $(2 \%(3 / 199))$.

Overall, the earlier computed tomography was performed the greater the incidence of significant cisternal blood and hydrocephalus. The incidence of proved aneurysms was lowest in Southampton and London (56 and 60\%, respectively).

\section{INFARCTS}

Nimodipine reduced significantly the number of primary outcome events - that is, the number of all cerebral infarcts-by $34 \%$ (table II). The number of definite infarcts was reduced by $37 \%$ (61 in placebo group, 39 in nimodipine; $\left.\chi^{2}=6 \cdot 10, \mathrm{df}=1 ; \mathrm{p}=0 \cdot 014\right)$. There was no evidence that the time from ictus or entry to first infarct was affected by treatment (ictus to infarct: nimodipine $9 \cdot 0$ days, range 1-38; placebo 8.4 days, range $1-40$ ). Late infarcts seemed to be associated with later operations, although the numbers were small. The effect of nimodipine was seen both before and after operation and in patients considered to be too ill for angiography or surgery.

The following factors were individually (rather than independently) associated with the rate of infarction: sex (marginal), loss of consciousness, angiographic findings, centre (marginal), hypertension, findings on computed tomography, and treatment. Adjusting simultaneously for findings on angiography and computed tomography and hypertension removed the effects of sex, loss of consciousness, and centre, but treatment remained highly significant $(p<0 \cdot 001)$. There was no evidence of any interactions between prognostic factors and treatment.

In summary, there was clear evidence of a reduced incidence of infarction in patients given nimodipine. The difference could not be explained by an imbalance in prognostic factors (indeed, adjusting for the prognostic factors if anything pointed to an enhanced benefit), and there was no evidence that the benefit of treatment was confined to a particular subgroup of the patients.

\section{OUTCOME}

Nimodipine reduced significantly the secondary outcome event-namely, the incidence of poor outcome (dead, vegetative state, and severe disability) -from $33 \%$ (91 patients) to $20 \%(55)$ - that is, by $40 \%$ (table II). Given the distribution of outcomes with the five category Glasgow outcome scale, there was clear evidence (significant at the $1 \%$ level) that the distribution of outcome changed with treatment: nimodipine shifted the pattern of outcomes towards

TABLE II-Effect of nimodipine on incidence of cerebral infarction and outcome after subarachnoid haemorrhage. Values are numbers (percentages) of patients unless stated otherwise

\begin{tabular}{|c|c|c|c|c|c|}
\hline & $\begin{array}{l}\text { Patients taking } \\
\text { nimodipine } \\
(\mathbf{n}=278)\end{array}$ & $\begin{array}{l}\text { Patients taking } \\
\text { placebo } \\
(\mathbf{n}=276)\end{array}$ & $\begin{array}{c}\text { Relative } \\
\text { reduction } \\
(\%)\end{array}$ & $\begin{array}{c}95 \% \\
\text { Confidence } \\
\text { interval }\end{array}$ & $\begin{array}{l}\text { Significance } \\
\text { (p value) }\end{array}$ \\
\hline Cerebral infarct & $61(22)$ & $92(33)$ & 34 & 13 to 50 & $0.003\left(\chi^{\prime}=8.99 ; \mathrm{df}=1\right)$ \\
\hline Poor outcome & $55(20)$ & $91(33)$ & 40 & 20 to 55 & $<0.001\left(\chi^{\prime}=12.41 ; \mathrm{df}=1\right)$ \\
\hline Rebleed & $25(9)$ & $38(14)$ & 35 & -5 to 59 & $0.077(\gamma=3.13 ; \mathrm{df}=1)$ \\
\hline
\end{tabular}

the good recovery end of the scale compared with placebo. One hundred and three patients died within 90 days after starting treatment, 43 in the group given nimodipine and 60 in that given placebo (table III).

TABLE III - Effect of nimodipine on score on Glasgow outcome scale three months after subarachnoid haemorrhage. Values are numbers of patients

\begin{tabular}{lcc}
\hline \multicolumn{1}{c}{ Outcome } & $\begin{array}{c}\text { Patients taking nimodipine } \\
(\mathrm{n}=278)\end{array}$ & $\begin{array}{c}\text { Patients taking placebo } \\
(\mathrm{n}=276)\end{array}$ \\
\hline Death & 43 & 60 \\
Vegetative state & 1 & 2 \\
Disability: & 11 & 29 \\
$\quad$ Severe & 24 & 16 \\
$\quad$ Moderate & 199 & 169 \\
Good recovery & & \\
\hline
\end{tabular}

Mortality in the two groups was not significantly different at the $5 \%$ level but had an observed significance level of $6 \%$ (relative reduction $29 \%(95 \%$ confidence interval -1 to 50$) ; \chi^{2}=3 \cdot 60, \mathrm{df}=1$ ).

The principal reason for the improvement in outcome was a reduction in the number of deaths and patients with disability considered to be due to episodes of delayed ischaemia. Other causes of death or disability (initial bleed, rebleeding, intracranial haematoma, operative complication, hydrocephalus, complications of treatment, other causes, and unknown) were similar in the two groups. In particular, recovery in patients who had sustained a severe initial bleed did not seem to be influenced (table IV).

TABLE IV-Causes of disability and death in patients taking nimodipine or placebo. Values are numbers (percentages) of patients ${ }^{\star}$

\begin{tabular}{|c|c|c|c|c|}
\hline \multirow[b]{2}{*}{ Cause } & \multicolumn{2}{|c|}{ Disability } & \multicolumn{2}{|c|}{ Death } \\
\hline & $\begin{array}{c}\text { Patients } \\
\text { taking } \\
\text { nimodipine } \\
(\mathrm{n}=278)\end{array}$ & $\begin{array}{c}\text { Patients } \\
\text { taking } \\
\text { placebo } \\
(\mathrm{n}=276)\end{array}$ & $\begin{array}{c}\text { Patients } \\
\text { taking } \\
\text { nimodipine } \\
(\mathbf{n}=278)\end{array}$ & $\begin{array}{c}\text { Patients } \\
\text { taking } \\
\text { placebo } \\
(\mathrm{n}=276)\end{array}$ \\
\hline Cerebral ischaemia & $20(7)$ & $34(12)$ & $17(6)$ & $25(9)$ \\
\hline Initial bleed & $19(7)$ & $17(6)$ & $7(3)$ & $10(4)$ \\
\hline Rebleeding & $5(2)$ & $7(3)$ & $14(5)$ & $24(9)$ \\
\hline Intracranial haematoma & & $1(<1)$ & $1(<1)$ & $3(1)$ \\
\hline Hydrocephalus & $1(<1)$ & $6(2)$ & $i(<1)$ & $2(1)$ \\
\hline Operative complication $\dagger$ & $8(3)$ & $6(2)$ & $4(1)$ & $3(1)$ \\
\hline Other & $5(2)$ & $2(1)$ & $1(<1)$ & $7(3)$ \\
\hline Unknown & & & $5(2)$ & \\
\hline
\end{tabular}

^Patients had more than one cause of disability or death.

†Complications of treatment with either nimodipine or placebo did not cause any disability or death.

The following factors were individually related to outcome: age, sex (marginal), loss of consciousness, score on Glasgow coma scale, angiographic findings, limb weakness, neck stiffness (marginal), hypertension, computed tomographic findings, and treatment. Adjusting simultaneously for age, loss of consciousness, score on Glasgow coma scale, and findings on angiography and computed tomography removed the effects of sex, limb weakness, neck stiffness, and hypertension, but treatment remained highly significant $(p=0.001)$. There was no evidence of any interaction between any prognostic factor and treatment.

In summary, there was clear evidence that treatment with nimodipine reduced the incidence of a poor outcome. This could not be explained by an imbalance in prognostic factors between the treatment groups. There was no evidence that the benefit of treatment was confined to any particular subgroup of the patients.

\section{REBLEEDS}

The incidence of rebleeding, either probable or definite, in patients treated with nimodipine was $9 \%$ 
compared with $14 \%$ in patients given placebo (table II). This difference had an observed significance level of $8 \%$. The following factors were individually associated with the risk of rebleeding: age, loss of consciousness, score on Glasgow coma scale (marginal), angiographic findings, hypertension (marginal), and computed tomographic findings. Adjusting simultaneously for age and angiographic findings removed the effects of the other variables, and there was little evidence of an effect of treatmen $(p=0 \cdot 21)$. This analysis should be given little weight because there were too few rebleeds to be confident of having identified relevant factors.

\section{BLOOD PRESSURE}

Nimodipine reduced progressively over 21 days both systolic (by a mean (SD) of $7 \cdot 1(18 \cdot 5) \mathrm{mm} \mathrm{Hg}$; $\mathrm{p}=0.05$ ) and diastolic blood pressure (by 3.6 $(11.0) \mathrm{mm} \mathrm{Hg} ; \mathrm{p}=0.094)$. This effect was possibly slightly more obvious in hypertensive patients, but it was not significant. Treatment had no consistent effect on the natural tendency of the pulse rate to increase progressively for 21 days after a subarachnoid haemorrhage (from a mean of 76 (12) to 85 (15) beats/ minute) or on fluid intake or urine output.

\section{ADVERSE REACTIONS}

Twenty seven adverse reactions ( 17 for nimodipine, 10 for placebo) were reported in 24 patients ( 14 given nimodipine, 10 given placebo). The highest numbers of reported events were for cardiovascular effects and effects on the liver and biliary system. Six adverse cardiovascular events were reported in the group given nimodipine (three of headache, one of flushing, one of hypertension, and one of hypotension) and three in the group given placebo (two of hypotension and one of headache).

Four adverse events concerned with the liver and biliary system were reported in patients given nimodipine (two of jaundice, two of liver function abnormalities) and five in those given placebo (one of jaundice, four of liver function abnormalities). Apart from two events of rash with nimodipine and one of rash with placebo all other adverse reactions were reported on only one occasion in both groups. The adverse reaction was considered to be sufficiently severe in eight patients taking nimodipine and three taking placebo for the treatment to be withdrawn. Routine haematological and biochemical laboratory data were comparable between the two groups.

\section{Discussion}

Our results show that oral nimodipine $60 \mathrm{mg}$ every four hours is well tolerated and reduces cerebral infarction and improves outcome after subarachnoid haemorrhage. This effect of treatment is seen in all clinical grades of patients both before and after operation. Although it is generally accepted that the peak incidence of delayed ischaemia is around seven to 10 days after the initial bleed, the need for early and also prolonged treatment was shown by the occurrence of infarction as soon as the first day and as late as the 40 th day after the initial bleed-only $37 \%$ of episodes of infarction occurred from the seventh to the 10th day.

Deterioration due to cerebral infarction was chosen as the primary outcome event for several reasons. Firstly, given the known actions of nimodipine, we considered that any beneficial effect would be shown through a prophylactic effect ${ }^{18}$ and a reduced occurrence of such episodes. Secondly, although nimodipine might help to preserve neuronal integrity in ischaemia, many other factors, including specific treatments such as induced hypertension, contribute to the natural recovery of function that occurs in some patients with delayed ischaemic deterioration. ${ }^{4}$ As a result the proportion of patients who are permanently disabled owing to ischaemia may provide a less sensitive assessment of a prophylactic measure. Furthermore, infarction can be diagnosed by clinical observation by sequential computed tomography, and at necropsy. We intentionally did not interpret particular episodes as being due to cerebral vasospasm. Arterial narrowing detected by angiography is only one of the many factors that lead to cerebral ischaemia after subarachnoid haemorrhage. Others include raised intracranial pressure (haematoma, hydrocephalus); episodes of hypotension, hypoxia, hypovolaemia, or hyponatraemia; predisposing factors (history of hypertension, advancing age, cigarette smoking); and surgery to clip the aneurysm. ${ }^{+5}$ Indeed, cerebral vasospasm alone seldom precipitates critical cerebral ischaemia unless the cerebral circulation can no longer compensate for proximal arterial constriction by dilatation of distal cerebral arterioles. So many factors contribute to delayed cerebral ischaemia that an appropriate subgroup would be difficult to define. Anyway, beneficial effect of nimodipine was seen in all the patients.

The assessment of outcome by the Glasgow outcome scale is widely accepted. To avoid unduly relying on the distinction between good recovery and moderate disability because such a distinction is particularly subject to variability in observers we distinguished poor outcomes (death, persistent vegetative state, and severe disability) from good recovery and moderate disability combined. The effect on outcome was greater perhaps than we would have expected from the reduction in the number of cerebral infarcts detected by computed tomography, given that there are other causes of bad outcome. Studies at necropsy have shown that cerebral infarcts may be small and diffusely distributed $^{3}$ and hence beyond the resolution of computed tomography. Nimodipine might protect partially against such minor diffuse infarction. We found no evidence that the beneficial effect of nimodipine was restricted to men, contrary to a recent study of patients with stroke. ${ }^{26}$

Results compatible with our findings were obtained in smaller controlled trials (table V) and in uncontrolled studies. ${ }^{1322}$ The pioneering study of Allen et al showed an effect of treatment only when a subgroup of patients with ischaemic neurological deficits attributed to

TABLE V-Comparison of results of double blind placebo controlled trials of oral nimodipine treatment in patients with subarachnoid haemorrhage

\begin{tabular}{|c|c|c|c|c|c|c|c|c|c|c|c|c|c|}
\hline \multirow[b]{2}{*}{ Study } & \multirow[b]{2}{*}{ Year } & \multirow[b]{2}{*}{ Place } & \multirow{2}{*}{$\begin{array}{c}\text { Dose } \\
\text { (every four hours } \\
\text { for } 21 \text { days) }\end{array}$} & \multirow{2}{*}{$\begin{array}{c}\text { No } \\
\text { of } \\
\text { centres }\end{array}$} & \multicolumn{4}{|c|}{ No of patients } & \multirow{2}{*}{$\begin{array}{l}\text { Grade } \\
\text { on } \\
\text { entry }\end{array}$} & \multicolumn{3}{|c|}{ No of patients with bad outcomes } & \multirow{2}{*}{$\begin{array}{c}\text { Relative } \\
\text { reduction } \\
(\%)\end{array}$} \\
\hline & & & & & Total & Exclusions & Nimodipine & Placebo & & Time & Nimodipine & Placebo & \\
\hline Allen $e t a l^{\prime}$ & 1983 & United States & $0.35 \mathrm{mg} / \mathrm{kg}$ & 5 & 125 & 9 & 56 & 60 & $1-2$ & 21 days & 1 & 8 & $86^{\star}$ \\
\hline Philippon et a $\left.\right|^{\text {th }}$ & 1986 & France & $60 \mathrm{mg}$ & 2 & 81 & 11 & 31 & 39 & $1-3$ & 21 days & 3 & 13 & $71^{\star}$ \\
\hline Neil-Dwyer et al: & 1987 & United Kingdom & $60 \mathrm{mg}$ & 1 & 75 & 25 & 25 & 25 & $1-5$ & 3 months & 6 & 12 & 50 \\
\hline Current trial & 1989 & United Kingdom & $60 \mathrm{mg}$ & 4 & 554 & 0 & 278 & 276 & $1-5$ & 3 months & 55 & 91 & 40 \\
\hline Petruk et al" & 1988 & Canada & $90 \mathrm{mg}$ & 17 & 188 & 34 & 72 & 82 & $3-5$ & $\left\{\begin{array}{l}21 \text { days } \\
3 \text { months }\end{array}\right.$ & $\begin{array}{l}53 \\
44\end{array}$ & $\begin{array}{l}67 \\
54\end{array}$ & $\begin{array}{r}10 \\
7\end{array}$ \\
\hline
\end{tabular}

^Related to spasm alone. 
vasospasm was defined: a significant benefit was not seen when the whole population was considered. Similar results have been reported for outcome at three months in patients of all clinical grades (table V)..$^{16} 1727$ Data from two controlled studies of intravenous nimodipine (1-2 mg/h for seven to 10 days ${ }^{28} 29$ and from open trials (preoperative, topical, and intravenous nimodipine for seven to 14 days followed by oral drug for up to 21 days) with historical controls ${ }^{1322}$ suggest that outcome in patients with ischaemia associated with vasospasm was improved.

Is intravenous nimodipine more effective than oral nimodipine? Although it is difficult to compare the patient populations, the reduction in the incidence of bad outcomes with intravenous nimodipine $(23 \%$ in the study of Ohman and Heiskanen ${ }^{28}$ and $36 \%$ in that of Jan $\left.e t a l^{29}\right)$ is similar to that in our study (40\%). During intravenous infusion $(2 \mathrm{mg} / \mathrm{h}$ ) the mean plasma concentration was reported to be $26.6(1.8) \mathrm{ng} / \mathrm{ml}$, while during oral treatment ( $45 \mathrm{mg}$ every four hours) the peak plasma concentration an hour after each dose ranged from 7 to $96 \mathrm{ng} / \mathrm{ml}$ and was $13.2 \mathrm{ng} / \mathrm{ml}$ (range $<3-38.8 \mathrm{ng} / \mathrm{ml}$ ) immediately before each tablet was taken..$^{30}$ The area under the curve was similar for the two methods of administration. ${ }^{31}$ Because protein binds $98 \%$ of the drug the ratio of cerebrospinal fluid to plasma concentration is only $0.005-$ the concentration in cerebrospinal fluid was $0.3(0.2) \mathrm{ng} / \mathrm{ml}$ compared with $77(34) \mathrm{ng} / \mathrm{ml}$ in plasma. ${ }^{31}$ Whether the difference in plasma concentration with oral and intravenous administration is reflected in the cerebrospinal fluid and whether such a difference affects nimodipine's efficacy in preventing cerebral infarction remains to be determined. Certainly, the available clinical evidence does not yet suggest any great difference. Oral administration permits prolonged treatment, which is useful if there is a long delay between the bleed and operation.

Oral nimodipine is well tolerated and in practice has not led to problems with interaction with anaesthetic agents. $^{3233}$ We found no suggestion of episodes of severe hypotension with nimodipine when compared with placebo. The mild reduction in blood pressure noted, particularly in the hypertensive patients, ${ }^{34}$ may have contributed to the improved outcome. ${ }^{35}$

Would a higher dose have any greater effect? A Canadian study used $90 \mathrm{mg}$ every four hours and, although it was a smaller study of patients with a poor grade, showed no significant hypotensive effects, ${ }^{17}$ but the effects on overall outcome were much less clear cut than in our trial. An unpublished study (Bayer trial No $3247 / 3293$ ) comparing 30,60 , and 90 mg orally every four hours did not show additional benefit with the $90 \mathrm{mg}$ dose when compared with the $60 \mathrm{mg}$ dose. In theory, a patient who metabolises nimodipine quickly might develop ischaemia and would benefit from a higher dose.

For how long should nimodipine be used? There was no evidence after nimodipine was discontinued of a late incidence of cerebral infarction compared with placebo. Any late infarcts seemed to occur after late operations. Prophylactic treatment should start therefore before any operation, whatever its timing. The effect of treatment was independent of when patients were given nimodipine within the 96 hours after ictus. The experimental data show that pretreatment within 20-30 minutes after occlusion of the middle cerebral artery in rats is protective. ${ }^{18}$ Cerebral ischaemia after subarachnoid haemorrhage is progressive so it is not surprising that nimodipine may be helpful even after clinical deterioration starts, ${ }^{29}$ but prophylaxis is to be preferred. Patients with negative results on high quality cerebral angiograms are at low risk of rebleeding or cerebral ischaemia and stopping nimodipine treatment might be considered to reduce costs. Exploratory analysis suggests, however, that there is still a trend in favour of nimodipine.

The mechanism of the beneficial effect of nimodipine is unclear. The original rationale for using calcium antagonists after subarachnoid haemorrhage was to reduce cerebral arterial spasm as seen on angiography. Our observation that spasm was not seen less often in treated patients accords with previous studies that used angiography or transcranial Doppler ultrasonography in patients and primates. ${ }^{12 \cdot 17}$ The data thus suggest that nimodipine neither prevents nor reverses cerebral vasospasm. Calcium channel blockers such as nimodipine may have an effect on cerebral arterioles that are below the limits of resolution of angiography and transcranial Doppler ultrasonography, ${ }^{36}{ }^{37}$ but cerebral blood flow studies do not support such a mechanism. ${ }^{27}$ The brain uses calcium for many other processes in addition to the control of cerebrovascular smooth muscle, and the diverse effects of calcium antagonists are becoming known. ${ }^{38-40}$

How should the fact that oral nimodipine $60 \mathrm{mg}$ every four hours reduces the incidence of cerebral infarction and improves outcome affect overal management of subarachnoid haemorrhage? Early surgery clearly will reduce the incidence of rebleeding but for most neurosurgical units in the United Kingdom more resources are needed to provide such a service. The proved efficacy of nimodipine and doctors' ability to assess recovery of normal cerebrovascular reactivity in individual patients ${ }^{41}$ will encourage selective early surgery and hence earlier transfer to neurosurgical units. Antifibrinolytic drugs reduce rebleeding in the short term but increase cerebral infarction. ${ }^{20}$ Nimodipine might reduce ischaemic complications produced by antifibrinolytic agents, ${ }^{17}$ but, as with the present trial, such a combination should not be used without the benefit of a substantial randomised double blind trial. Finally, the introduction of nimodipine for subarachnoid haemorrhage is not displacing another treatment. The apparent additional expense must, however, be viewed in the context of the overall cost effectiveness of managing a patient with subarachnoid haemorrhage from ictus to final outcome and consideration should not be restricted simply to the immediate burden on neurosurgical units' drug budget.

We thank Dr L Porto and Mrs Julia Duffy of Bayer UK for their collaboration and punctilious attention to detail; our colleagues for permission to enter their patients into the trial and for their enthusiastic support $(\mathrm{Mr} \mathrm{J}$ Brice and $\mathrm{Mr} \mathrm{J}$ Garfield in Southampton; Mr M Rice-Edwards in London; $\mathrm{Mr} J$ Miles, $\mathrm{Mr} \mathrm{R}$ V Jeffreys, and $\mathrm{Mr}$ G Findlay in Liverpool; and $\mathrm{Mr} \mathrm{T} \mathrm{A} \mathrm{H}$ Hide, $\mathrm{Mr} \mathrm{S}$ Galbraith, $\mathrm{Mr} \mathrm{J}$ Turner, $\mathrm{Mr}$ $\mathrm{R}$ Johnston, Mr P Stanworth, and Mr D Mendelow in Glasgow); and Mrs Jane Roberts for her help with managing the trial in Southampton. Bayer UK provided the funding required to support the study in the four centres; the conduct of the trial and statistical assessment were our independent responsibilities.

1 Allen GS, Ahn HS, Preziosi TJ, et al. Cerebral arterial spasm-a controlled rial of nimodipine in patients with subarachnoid hemorrhage. $N$ Englf $\mathrm{Med}$ 983;308:619-24

2 Anonymous. Calcium antagonists and aneurysmal subarachnoid haemorrhag [Editorial]. Lancet 1983;ii: 141-3.

3 Crompton MR. Cerebral infarction following the rupture of cerebral berry aneurysms. Brain 1964;87:263-79.

4 Symon L. Disordered cerebrovascular physiology in aneurysmal subarachnoid haemorrhage. Acta Neurochir (Wien) 1978;41:7-22.

5 Pickard JD, Matheson M, Patterson J, Wyper D. Prediction of late ischemic complications after cerebral aneurysm surgery by the intraoperative measurement of cerebral blood flow. I Neurosurg 1980;53:305-8.

6 Simeone FA, Vinall P. Mechanisms of contractile response of cerebral artery to externally-applied fresh blood. F Neurosurg 1975:43:37.47.

7 Brandt L, Andersson KE, Edvinsson L, Ljunggren B. Effects of extracellula calcium and of calcium antagonists on the contractile responses of isolated calcium and of calcium antagonists on the contractile responses of isolated
human pial and mesenteric arteries. F Cereb Blood Flow Metabol 1981;1 human pial and

8 Kazda S, Towart R. Nimodipine: a new calcium antagonistic drug with a preferential cerebrovascular action. Acta Neurochir (Wien) 1982;63:259-65. 9 Harper AM, Craigen L, Kazda S. Effect of the calcium antagonist, nimodipine, 
on cerebral blowd flow and metabolism in the primate. $\mathcal{f}$ Cereh Blood Flow Metabol 1981;1:349-56.

10 Harris RJ, Branston NM, Symon L, Bavhan M, Watson A. The effects of a calcium antagonist, nimodipine, upon physiological responses of the cerebral vasculature and its possible influence upon focal cerebral ischemia. Stroke 1982:13:759-66.

11 Haws $\mathrm{CH}$, Heistad DD. Effects of nimodipine on cerebral vasoconstrictor responses. Am F Physiol 1984;247: H170-6.

12 Grotenhuis JA, Bettag W, Fiebach BJO, Dabir K. Intracarotid slow bolus injection of nimodipine during angiography for treatment of cerebral vasospasm after subarachnoid hemorrhage. I Neurosurg 1984;61:231-40.

13 Ljunggren B, Brandt L, Saveland $\mathrm{H}$, et al. Outcome in 60 consecutive patients treated with early aneurysm operation and intravenous nimodipine. 7 Neurosurg 1984;61:864-73.

It Espinosa F, Weir B, Overton 'T, et al. A randomized placebo-controlled double-blind trial of nimodipine after subarachnoid hemorrhage in monkeys. I. Clinical and radiological findings. I Neurosurg 1984;61:231-40.

15 Nosko $M$, Weir B, Krueger C, et al. Nimodipine and chronic vasospasm in monkeys. I. Clinical and radiological findings. Neurosurgery 1985;16:129-36.

16 Philippon J, Grob R, Dagreou F, Guggiari M, Rivierez M, Viars P. Prevention of vasospasm in subarachnoid haemorrhage. A controlled study with nimodipine. Acta Neurochir (Wien) 1986;82:110-4.

17 Petruk KC, West M, Mohr G et al Nimodipine treatment in poor grade aneurysm patients. Results of a multicentre, double-blind, placebo grade aneurysm patients. Results of a multice

18 Gotoh O, Mohamed AA, McCulloch J, Graham DI Harper AM Teasdale GM. Nimodipine and the hemodynamic and histopathological consequences of middle cerebral artery occlusion in the rat. 7 Cereb Blood consequences of middle cer

19 Shaw MDM, Foy PM, Conway M, et al. Dipyridamole and post-operative ischemic deficits in aneurysmal subarachnoid hemorrhage. I Neurosur 1985;63:699-703.

20 Vermeulen $\mathrm{M}$, Lindsay $\mathrm{KW}$, Cheah $\mathrm{MF}$, et al. Antifibrinolytic treatment in subarachnoid hemorrhage. $N$ Engl f Med 1984;311:432-7.

21 Mohsen F, Pomonis S, Illingworth R. Prediction of delayed cerebral ischaemia after subarachnoid haemorrhage by computed tomography. I Neur: Neurosurg Psychiatry 1984;47:1197-202.

22 Auer LM. Acute operation and preventive nimodipine improve outcome in patients with ruptured aneurysms. Neurosurgery 1984;15:57-66.

23 Teasdale GM, Lindsay KW, Allardyce G, Dharker S, Ward P. Standardized clinical grading of paients with subarachnoid haemorrhage: a uniform clinical grading of patients with subarachnoid haemorrhage: a uniform international system? In. Auer

24 Teasdale GM. A universal subarachnoid haemorrhage scale: report of a committee of the World Federation of Neurosurgical Societies. I Neurol Neurosurg Psychiatry 1988;51:1457.

25 Jennett B, Bond $M$. Assessment of outcome after severe brain damage. A practical scale. Lancet $1975 ;$ i: $480-4$.
26 Gelmers $\mathrm{HJ}$, Gorter $\mathrm{K}$, de Weerdt $\mathrm{CJ}$, Wiezer HJA. A controlled trial of nimodipine in acute ischemic stroke. $N$ Engl f Med 1988:318:203-7.

7 Neil-Dwyer G, Mee E, Dorrance D, Lowe D. Early intervention with nimodipine in subarachnoid haemorrhage. Eur Heart $\mathcal{f}$ 1987;8 (suppl K): 41-7.

28 Ohman J, Heiskanen O. Effect of nimodipine on the outcome of patients after aneurysmal subarachnoid hemorrhage and surgery. I Neurosurg 1988;69: 683-6.

29 Jan M. Buchheit F, Tremoule M. Therapeutic trial of intravenous nimodipine in patients with established cerebral vasospasm after rupture of intracranial aneurysms. Neurosurgery 1988;23:154-7.

30 Vinge $\mathrm{E}$, Andersson KE, Brandt L, Ljunggren B, Nilsson LG, RosendalHelgesen S. Pharmacokinetics of nimodipine in patients with aneurysmal subarachnoid haemorrhage. Eur f Clin Pharmacol 1986;30:421-5.

31 Rämsch KD, Ahr G, Tettenborn D, Auer LM. Overview on pharmacokinetics of nimodipine in healthy volunteers and in patients with subarachnoid haemorrhage. Neurochirurgia (Stuttg) 1985;28(suppl 1):74-8.

32 Stulleken EH, Balestrieri FJ, Prough DS, McWhorter JM. The hemodynamic effects of mimodipine in patients anesthetised for cerebral aneurysm clipping. Anesthesiology 1985;62:346-8.

33 Merin RG. Calcium channel blocking drugs and anesthetics -is the drug interaction beneficial or detrimental? Anesthesiology 1987;66:111-3.

34 Tettenborn D, Dicka J, Volberg E, Düdden P. Blood pressure and heart rate during treatment with nimodipine in patients with subarachnoid rate during treatment with nimodipine in patients with

35 O'Neill P, West CR, Chadwick DW, et al. Post-ictal blood pressure in aneurysmal subarachnoid haemorrhage. Br f Neurosurg 1988;2:153-60.

36 Brandt L, Ljunggren B, Andersson KE, et al. Effects of topical application of a calcium antagonist (nifedipine) on feline cortical pial microvasculature under normal conditions and in focal ischemia. I Cereb Blood Flow Metabol $1983 ; 3: 44-50$

37 Takayasu M, Bassett JE, Dacey RG. Effects of calcium antagonists on intracerebral penetrating arterioles in rats. I Neurosurg 1988;69:104-9.

38 Middlemiss DN, Spedding $M$. A functional correlate for the dihydropyridine binding site in rat brain. Nature 1985;314:94-6.

39 Pickard JD, Walker V, Vile J, Perry S, Smythe PJ, Hunt R. Oral nimodipine reduces prostaglandin and thromboxane production by arteries chronically exposed to a periarterial haematoma and the antifibrinolytic agent tranexamic acid. $\mathcal{F}$ Neurol Neurosurg Psychiatry 1987;50:727-31

40 Phillis JW, O'Regan MH, Walter GA. Effects of nifedipine and felodipine on adenosine and inosine release from the hypoxemic rat cerebral cortex. ICereb Blood Flow Metab 1988;8:179-85.

41 Pickard JD, $\mathrm{Read} \mathrm{DH}$, Lovick $\mathrm{AHJ}$. Preoperative assessment of cerebrovascular reactivity following subarachnoid haemorrhage-clinical correlations. In: Auer LM, ed. Timing of aneurysm surgery. Berlin: Walter de Gruyter, 1985:47-51.

(Accepted 20 December 1988)

\section{Department of \\ Epidemiology, Erasmus \\ University Medical School, \\ Rotterdam, \\ The Netherlands \\ Jacqueline C M Witteman, \\ MSC, resident in epidemiology \\ Diederick E Grobbee, MD, \\ senior lecturer in epidemiology \\ Frans J Kok, PHD, senior \\ lecturer in epidemiology \\ Albert Hofman, MD, \\ professor of epidemiology \\ Hans A Valkenburg, MD, emeritus professor of \\ epidemiology}

Correspondence to:

Miss Witteman.

BrMed f 1989;298:642-4

\title{
Increased risk of atherosclerosis in women after the menopause
}

\author{
Jacqueline C M Witteman, Diederick E Grobbee, Frans J Kok, Albert Hofman, Hans A Valkenburg
}

Abstract

An increase in the incidence of cardiovascular disease has generally been observed in postmenopausal women, but there have been few studies of the association between menopausal state and atherosclerosis. In this study 294 premenopausal and 319 postmenopausal women aged 45 to 55 were examined radiographically for calcified deposits in the abdominal aorta, which have been shown to represent intimal atherosclerosis. Aortic atherosclerosis was present in eight $(3 \%)$ of the premenopausal women and in $38(12 \%)$ of the postmenopausal women. After adjustments for age and other indicators of cardiovascular risk women with a natural menopause had a 3.4 times greater risk of atherosclerosis than premenopausal women $(95 \%$ confidence interval 1.2 to $9.7 ; p<0.05$ ); women who had had a bilateral oophorectomy had a 5.5 times greater risk $(1.9$ to $15.8 ; p<0.005)$. No excess risk of atherosclerosis was observed among women who had had a hysterectomy without removal of both ovaries.

These results suggest that when oestrogen production stops, either naturally or after surgery, the risk of atherosclerosis is increased.

\section{Introduction}

An increase in the incidence of cardiovascular disease after the menopause has generally been observed, though not all studies agree with this finding. ${ }^{12}$ Non-invasive assessment of atherosclerosis may help to clarify this issue. Information on the extent of atherosclerosis in premenopausal and postmenopausal women has been gained mainly from necropsy studies. Compared with women with intact ovaries women who had had bilateral oophorectomy had an excess of coronary atherosclerosis, which approached that in men. ${ }^{34}$ We investigated the association between menopausal state and the presence of calcified deposits in the abdominal aorta as seen on lateral radiographs of the lumbar spine. The presence of such deposits represents true intimal atherosclerosis ${ }^{5}$ and is a strong predictor of death from cardiovascular causes. ${ }^{6}$

\section{Subjects and methods}

A population study on chronic diseases was conducted in Zoetermeer, a suburb of The Hague in The Netherlands, between 1975 and 1978. All inhabitants of one rural and one urban district who were aged 5 years and over were invited for a medical examination. The response rate among middle aged women was $77 \%$. Details of the initial study have been reported.' All women aged 45 to 55 without a history of cardiovascular disease $(n=676)$ were eligible for our study. The lower age limit was 45 because radiography of the lumbar spine was performed from this age onwards. The upper age limit of 55 was chosen to include sufficient premenopausal and postmenopausal women of similar ages.

We diagnosed atherosclerosis by radiographic detection of calcified deposits in the abdominal aorta. ${ }^{6}$ Lateral radiographs of the lumbar spine were available 